\title{
ENSINO DE HISTÓRIA E EDUCAÇÃO PATRIMONIAL EM RIO GRANDE/RS: PROPOSIÇÃO DE ATIVIDADES NO "JOGO DE ESCALAS"
}

\author{
HISTORY TEACHING AND HERITAGE EDUCATION IN RIO GRANDE/RS: \\ PROPOSITION OF ACTIVITIES IN THE "SCALE GAME"
}

Matheus Balbueno Pinto ${ }^{1}$

\begin{abstract}
RESUMO: O texto apresenta considerações para o estabelecimento de relações práticas e concretas entre o ensino de História e a Educação Patrimonial no município do Rio Grande/RS, podendo elas serem utilizadas como base para replicações em outros contextos locais. A ideia passa por um breve esboço teórico e metodológico sobre a conceituação de patrimônio histórico cultural e a aplicabilidade da Educação Patrimonial, além do diálogo com a educação. O foco, então, centra-se no ensino de História a partir desses pontos e levando em consideração uma dinâmica no "jogo de escalas" entre o macro e micro. As relações estabelecidas se dão entre os conteúdos tradicionais do currículo escolar de História e os bens culturais rio-grandinos a serem percebidos com a metodologia da Educação Patrimonial na dinâmica entre escalas. Assim, o macro representado pelos conteúdos curriculares - encontra o micro - representado pelos bens culturais - na vivência do ensino de História. Por fim, chega-se ao aspecto pedagógico do patrimônio a ser valorizado no ensino de História, a partir da oferta de uma base de material de apoio aos professores, beneficiando as áreas.
\end{abstract}

Palavras-chave: Ensino de história. Patrimônio. Educação patrimonial. Escalas.

\begin{abstract}
The text presents considerations for the establishment of practical and concrete relations between History teaching and Heritage Education in the city of Rio Grande/RS, which also can be used as a basis for replications in other local contexts. The idea goes through a brief theoretical and methodological outline about the conceptualization of historical cultural heritage and the applicability of Heritage Education, besides the dialogue with education. The focus, then, is on History teaching from these points and taking into account a dynamic in the "scale game" between the macro and micro aspects. The established relationships take place between the traditional contents of the school History curriculum and the cultural goods of Rio Grande to be perceived with the methodology of Heritage Education in the dynamics between scales. Thus, the macro aspect - represented by the curricular contents - finds the micro aspect - represented by the cultural goods - in the experience of History teaching. Finally, the text reach heritage's pedagogical aspect to be valued in History teaching, from the provision of a base of material to support teachers, benefiting those areas.
\end{abstract}

Keywords: History teaching. Heritage. Heritage education. Scales.

\footnotetext{
${ }^{1}$ Licenciado em História. Acadêmico do Mestrado Profissional em História da Universidade Federal do Rio Grande (FURG). Professor de História no Ensino Médio da rede privada nos colégios Kyrios e Marista São Francisco em Rio Grande/RS.
} 


\section{Introdução}

O propósito central do presente texto é propor o estabelecimento de uma possível relação prática e concreta entre o ensino de História e a Educação Patrimonial, valorizando uma dinâmica entre escalas de análise, com foco na educação básica da cidade do Rio Grande/RS. A ideia fundamental é a inserção da metodologia da Educação Patrimonial em alguns dos conteúdos de História previstos no currículo tradicional da disciplina. Assim, a temática transversal do patrimônio - que já se faz presente em algumas realidades escolares - passa a ser inserida nas aulas de História, por meio da Educação Patrimonial, para aproximar os estudantes dos conceitos e, essencialmente, de vivências práticas sobre o que é trabalhado. "Desde os anos de 1980, levar em consideração as escalas de observação assumiu um lugar importante no debate dos historiadores" (REVEL, 2010, p. 434). Logo, o estudo de conteúdos mais generalizantes da disciplina organizados no currículo (escala macro) podem vir a ser percebidos pela realidade do patrimônio rio-grandino (escala micro).

A ideia origina-se a partir de algumas experiências, sendo a principal delas a disciplina de "Educação Patrimonial" - ministrada pela professora Carmem Schiavon - no curso de Licenciatura em História da Universidade Federal do Rio Grande (FURG). Na disciplina, percebeu-se que o ensino de História pode vir a ser intimamente ligado à Educação Patrimonial, beneficiando as duas áreas em diálogo e, ainda mais, os estudantes alvo dessas práticas. Isso se torna possível, pois, na definição do Instituto do Patrimônio Histórico e Artístico Nacional:

A Educação Patrimonial constitui-se de todos os processos educativos formais e não formais que têm como foco o patrimônio cultural, apropriado socialmente como recurso para a compreensão sócio-histórica das referências culturais em todas as suas manifestações, a fim de colaborar para seu reconhecimento, sua valorização e preservação. Considera-se, ainda, que os processos educativos devem primar pela construção coletiva e democrática do conhecimento, por meio da participação efetiva das comunidades detentoras e produtoras das referências culturais, onde convivem diversas noções de patrimônio cultural (IPHAN, 2014). 
Diante do excerto acima, entende-se que a Educação Patrimonial pode fazer parte do processo de ensino-aprendizagem de História como um elemento de mediação entre os estudantes e o patrimônio rio-grandino. Esse patrimônio, visto, aqui, como recurso, auxiliaria não apenas na compreensão sócio-histórica das referências culturais, mas também dos conteúdos trabalhados em sala de aula de acordo com o currículo. Logo, a construção do conhecimento histórico dar-se-ia de forma coletiva e ativa com a aproximação dos estudantes às referências culturais e, por meio delas, aos conteúdos da disciplina. Farinatti (2008, p. 62) lembra do movimento da historiografia em que "[...] foi importante a reinvenção das fontes e o questionamento às análises feitas 'de longe' [...]". Sendo assim, temas distantes no espaço e no tempo, alocados em uma escala mais ampla, seriam vistos por meio da Educação Patrimonial, em uma escala diminuta, à medida que o patrimônio seria reconhecido, valorizado e preservado.

Ainda, na trajetória dos estudos da disciplina de Educação Patrimonial na graduação, notou-se certa dificuldade em exemplificações concretas, ligadas à realidade do município, de meios para colocar a metodologia em prática no ensino de História. Vale destacar aqui o exemplo mais utilizado e que vem a servir como orientação para o desenvolvimento da ideia aqui exposta: o estudo da Revolução Industrial pelo contexto local, a partir da fábrica Rheingantz. Nesse exemplo basilar, aproximar-se-ia os alunos de um conteúdo distante no espaço e no tempo - Revolução Industrial, Inglaterra, séculos XVIII e XIX - por meio do patrimônio rio-grandino, que fez parte direta e indiretamente do cotidiano de muitas famílias - fábrica Rheingantz.

Ademais, outras experiências foram constituídas a partir da participação no Programa Institucional de Bolsas de Iniciação à Docência (PIBID) e da realização do Estágio Supervisionado em História entre 2016 e 2018. A atuação ao longo de quase dois anos no PIBID ofereceu uma perspectiva singular de entendimento da realidade escolar, que se confirmou no Estágio Supervisionado em História. O patrimônio, mesmo que aos poucos, é inserido de forma crescente nas aulas de História e, quando é apresentado, há uma boa aceitação das turmas. Os conteúdos trabalhados na perspectiva do patrimônio e pela aplicação da metodologia da Educação Patrimonial, focados no município do Rio Grande e nos bens culturais próximos aos alunos, acabam adquirindo maior significado e 
auxiliando na percepção do sentimento de pertencimento ao município e à História. Por fim, faz-se necessário lembrar também da experiência adquirida com as leituras e as discussões propostas pela disciplina de "Teoria e metodologia da pesquisa no ensino de história"2 que auxiliaram na reflexão sobre a possibilidade de abrir espaço para um "jogo de escalas" na análise histórica e, a partir disso, no ensino de História.

Os pontos fulcrais desse texto estão intrinsecamente ligados ao desenvolvimento de práticas e de pesquisas no campo do ensino de História, pois estão sendo propostas vivências de ensino-aprendizagem a serem trabalhadas e apresentadas pela pesquisa. A temática trabalhada, ensino de História e Educação Patrimonial, é atual e necessária, mas tem-se compreensão de que o proposto pela formação inicial dos professores de História ainda não reflete a totalidade dessa importância. Sabe-se que

[...] a Educação Patrimonial é um tema em voga e que independentemente da atuação da escola, a sociedade vem desenvolvendo uma concepção própria de patrimônio, a partir de princípios nem sempre definidos e por meio de uma diversidade de ferramentas (MAGALHÃES; ZANON; BRANCO, 2009, p. 49-50).

Assim, a intenção também é garantir alguma contribuição ao meio acadêmico e profissional. Afinal, como bem destaca Cecília Londres em artigo sobre o patrimônio cultural na formação das novas gerações, publicado no caderno temático de Educação Patrimonial do IPHAN,

[...] o grande desafio para se alcançar os objetivos mencionados neste texto está na elaboração de subsídios - em termos de produção de material de apoio e de processos de formação de pessoal - voltados para o desenvolvimento de atividades que contribuam para se difundir, sobretudo junto às crianças e jovens, uma 'consciência preservacionista', o que pressupõe [...] não apenas a transmissão de conhecimentos, como o estímulo à curiosidade, à criatividade e ao prazer. (LONDRES, 2012, p. 21).

Logo, o que se intenciona aqui vai ao encontro das demandas contemporâneas nas áreas do patrimônio, da Educação Patrimonial e do ensino de História. O desenvolvimento dessa "consciência preservacionista" está diretamente ligado aos mecanismos educativos formais e não-formais, por

\footnotetext{
2 Ministrada pelo professor José Carlos Cardozo, no Mestrado Profissional em História da FURG.
} 
conseguinte, ao ensino de História também nos anos finais do ensino fundamental e no ensino médio da educação básica do Rio Grande. O patrimônio, assim como outras temáticas em voga, é encarado como questão importante e muito presente no cotidiano, fazendo com que seja possível trabalhá-lo em todas as áreas ou disciplinas. Não cabe à História, então, furtar-se a ocupar esse espaço, mas também desenvolver esses temas na disciplina, beneficiando-a, pois, tal como ressalta Bensa (1998, p. 71), "uma tal visão unificada do mundo social se rompe quando procedemos a uma diversificação das escalas de análise [...]". Logo, a partir da ideia presente nesse texto, a ser desenvolvida e aprimorada pela prática profissional dos professores, facilitar-se-ia o entendimento dos conteúdos da disciplina de História por meio de um importante processo de apropriação e valorização do patrimônio, nesse caso, rio-grandino.

\section{Patrimônio, Educação Patrimonial e ensino de História}

O referencial institucional que embasa a rede pública municipal de educação do Rio Grande já apresenta o patrimônio como um dos temas transversais a serem trabalhados nos anos finais do ensino fundamental (SMED, 2015). Ainda assim, faz-se necessário entender esse conceito de patrimônio a ser secundado neste projeto, pois o trabalho proposto a ser realizado no ensino de História dar-se-á também a partir dele. Logo, destaca-se a síntese de Cecília Londres:

\footnotetext{
O termo patrimônio, de origem latina (patrimonium), designa os bens recebidos por herança paterna, familiar, e, por extensão, vem sendo utilizado para nomear o legado de uma geração a outra, não apenas no âmbito da família, como também dos grupos sociais, dos Estados nacionais e mesmo da humanidade. A ideia de transmissão ao longo do tempo é, portanto, constitutiva da noção de patrimônio (LONDRES, 2012, p. 14, grifo do autor).
}

Desse modo, percebe-se que inicialmente o patrimônio está ligado à permanência e à transmissão de legados ao longo do tempo, seja sob uma ótica reduzida (família) ou ampliada (humanidade). Assim, não chega a causar espanto que o patrimônio seja recorrentemente associado ao que é antigo e que, por isso, venha se investindo na "desnaturalização do patrimônio" (OLIVEIRA, 2009). Esse processo parte das bases do processo educacional, isto é, a formação de professores, e chega à comunidade por meio das instituições 
escolares. O ensino de História, então, atrela-se aqui à concepção de que o tema transversal do patrimônio deve ser trabalhado nas aulas sob essa perspectiva de "desnaturalização" a fim de que se chegue a uma ideia de patrimônio cultural.

A "desnaturalização" do patrimônio é necessária para que se evite contribuir com a continuidade da ideia de que apenas o tangível, institucional e antigo configura-se como um bem patrimonial. Nessa perspectiva, vai-se ao encontro do pensamento de Gil e Almeida (2013, p. 133):

\begin{abstract}
se por muito tempo o conceito de patrimônio ficou restrito aos bens materiais, especialmente o arquitetônico, [...] hoje essa noção se amplia para abranger o patrimônio cultural, que engloba aspectos históricos, mas também ecológicos, artísticos e científicos.
\end{abstract}

Com isso, consolida-se também a visão de patrimônio vivo, como identificado por Horta, Grunberg e Monteiro (1999), para que os diversos patrimônios não sejam reduzidos simplesmente ao edificado, mas abarquem as diferentes formas de expressão e os múltiplos sentidos e significados culturais que podem ser atribuídos tanto aos legados arquitetônicos quanto às demais manifestações.

Nesse sentido, chega-se a essa perspectiva que entende o patrimônio cultural como "[...] o conjunto de bens materiais e práticas culturais que se destacam no ambiente urbano e nas manifestações populares por representarem heranças técnicas, estéticas e culturais de diferentes épocas e gerações" (ROSSI, 2009 , p. 9). A partir dessa estruturação de conceitos, torna-se possível verificar que o patrimônio cultural pode vir a ser um grande aliado do ensino de História, pois acaba sendo um meio singular de entendimento do passado e do presente, também por meio das mudanças e das permanências no espaço e no tempo. Como apontado por Rossi (2009), é um importante elemento constitutivo de nossa identidade, também de alteridade e, inclusive devido a isso, apresenta-se como instrumento fundamental para auxiliar no processo de aproximação dos estudantes aos conteúdos de História.

Diante disso, opta-se pela utilização do conceito de bens culturais ao se estabelecer as relações com o patrimônio rio-grandino. Grunberg (2000, p. 162) define os bens culturais como "[...] aqueles através dos quais podemos compreender e identificar a cultura de um povo, em determinado lugar e 
momento histórico". Assim, ao propor as situações de aproximação dos alunos em relação aos conteúdos de História pela utilização do patrimônio, entende-se esse patrimônio na figura dos bens culturais do município que, ainda segundo Grunberg (2000, p. 163), "[...] podem ser também consagrados ou não, de acordo com os valores e a ideologia que ditaram e ditam os critérios para sua preservação". As aulas, consequentemente, também partem em direção da construção da mais ampla "consciência preservacionista" que não se limita ao que já está definido como digno desse tratamento. Ainda, os bens culturais, consagrados ou não, passam a adquirir também o caráter de recursos educacionais, já que a proposta central é o ensino de História a partir deles.

Nesse momento, vale destacar que o caráter pedagógico do patrimônio já está inserido no debate público há algum tempo. O anteprojeto de Mário de Andrade, para a criação do Serviço do Patrimônio Histórico e Artístico Nacional, já previa que o patrimônio não está ligado única e exclusivamente à preservação, mas também ao ensino (FLORÊNCIO, 2012). Então, propõe-se a mediação entre os aspectos preservacionistas e educativos do patrimônio por meio de sua conexão com o ensino de História. A ideia é que os bens culturais rio-grandinos aproximem os alunos dos conteúdos de História, ao passo que esses conteúdos também possibilitem uma ligação dos alunos aos bens culturais do seu município.

\begin{abstract}
Os bens culturais são o ponto de partida do qual se originam uns sem número de informações, conhecimentos e enfoques. Eles servem como fonte primária de observação aberta à exploração. Neles se condensa um amplo leque de manifestações e relações humanas, tanto existidas como existentes. A proposta de utilizálos como recursos educacionais, aplicando uma metodologia específica de trabalho, a chamamos de Educação Patrimonial (GRUNBERG, 2000, p. 167)
\end{abstract}

Nisto, portanto, a ideia está inserida na lógica proposta por essas considerações teóricas, fazendo com que se chegue a um marco metodológico fundamentado nelas. A relação entre patrimônio e ensino, ou seja, a utilização dos bens culturais como recursos educacionais, passa pela metodologia específica da Educação Patrimonial. "Às ações educativas que envolvem a sensibilização ao patrimônio cultural damos o nome de educação patrimonial, conceito que deve ser entendido aqui como um processo ativo de conhecimento, 
apropriação e valorização de nossa cultura" (ROSSI, 2009, p. 9). Com isso, a visão estabelecida aqui é a de que as aulas de História também passem a sensibilizar os estudantes em relação ao patrimônio cultural e a serem sensibilizadas por ele. Passa-se a perseguir um objetivo de uma dinâmica entre escalas de análise calcado metodologia da Educação Patrimonial para que o patrimônio cultural rio-grandino venha a ser apropriado pelos estudantes e utilizado por eles como meio de aproximação dos conteúdos trabalhados nas aulas de História.

Florêncio (2012), a partir de Horta, Grunberg e Monteiro (1999), indica que a utilização da nomenclatura Educação Patrimonial no Brasil remonta à década de 1980, inspirando-se no trabalho inglês denominado Heritage Education; entretanto, ainda ligada aos museus e aos monumentos históricos com fins educacionais. Maria Ângela Salvadori amplia o sentido do termo no momento em que afirma:

\begin{abstract}
Hoje, porém, ele é usado para um processo ainda mais amplo de valorização e preservação de bens materiais ou imateriais que ajudam a compreender melhor tanto o estilo de vida daquele que o produziram quanto o nosso próprio. Nesse sentido, a educação patrimonial envolve de modo evidente o ensino de história enquanto entendimento de mudanças espaço-temporais, reconhecimento de permanências e embate entre diferentes sujeitos e grupos em torno de suas propostas políticas, simbolizadas pelos bens que procuram preservar/destruir (SALVADORI, 2008, p. 37).
\end{abstract}

Com base nestas considerações, adota-se a definição de Educação Patrimonial " $[. .$.$] como o ensino centrado nos bens culturais, como a metodologia$ que toma estes bens como ponto de partida para desenvolver a tarefa pedagógica; que considera os bens culturais como fonte primária de ensino" (GRUNBERG, 2000, p. 167-168). O propósito é trazer para o ensino de História, justamente, os bens culturais como uma fonte primária de ensino para que venha a ocorrer a concretização da possibilidade de aproximação dos alunos aos conteúdos trabalhados e ao patrimônio. Afinal, como destacam Viana e Mello (2013, p. 50), "[...] essa relação favorece a criação de pontos de contato com o universo cultural dos alunos, permitindo a apreensão significativa de assuntos considerados de difícil compreensão, por sua distância no tempo e no espaço $[\ldots]^{\prime \prime}$. Os bens culturais passam a ser, então, objetos de interesse por definição 
para serem apropriados pelos estudantes e utilizados como referências para um entendimento mais próximo, real e concreto dos conteúdos de História (do micro ao macro).

A relação entre o ensino e a preservação do patrimônio também se faz presente, pois, conforme Horta, Grunberg e Monteiro (1999, p. 6), "o conhecimento crítico e a apropriação consciente pelas comunidades do seu patrimônio são fatores indispensáveis no processo de preservação sustentável desses bens, assim como no fortalecimento dos sentimentos de identidade e cidadania". Nessa linha, o ensino de História passa a ocupar também parte desse espaço, trazendo o patrimônio rio-grandino para as discussões sobre os conteúdos das aulas e, ao fazer isso, garantindo a construção e/ou o fortalecimento de laços entre os estudantes e os bens culturais do município. Por esse motivo, a Educação Patrimonial passa a ser vista como uma metodologia com etapas específicas a serem seguidas, mas também como um processo contínuo na conscientização daqueles que dela se utilizam para alcançar determinados objetivos específicos.

Por consequência, concebe-se também que

[...] a Educação Patrimonial deve ser tratada como um conceito basilar para a valorização da diversidade cultural, para o fortalecimento de identidades e de alteridades no mundo contemporâneo e como um recurso para a afirmação das diferentes maneiras de ser e de estar no mundo (FLORÊNCIO, 2012, p. 24).

Dessa forma, essa realização também estreita a ligação entre a Educação Patrimonial e o ensino de História pela perspectiva de entendimento das identidades e do incentivo ao respeito ao que pode ser vivido e entendido de formas diferentes nos locais de convívio dos alunos no município do Rio Grande. O "interesse público", uma das bases da preservação do patrimônio (LONDRES, 2012), é complexo e múltiplo, permeado de valores distintos nas comunidades. As práticas relacionando o ensino de História aos bens culturais rio-grandinos através da Educação Patrimonial passam a ser mais uma forma de reafirmação das identidades singulares e de aceitação e incentivo à expressão plural da diversidade.

Isto posto, cabe apontar que os bens culturais rio-grandinos selecionados para o estabelecimento de relação com os conteúdos de História podem vir a ser 
pensados por meio da Educação Patrimonial, pois "a metodologia específica da Educação Patrimonial pode ser aplicada a qualquer evidência material ou manifestação de cultura [...]" (HORTA; GRUNBERG; MONTEIRO, 1999, p. 6). Visa-se, então, aplicar e desenvolver a metodologia da Educação Patrimonial com foco no ensino de História, levando em consideração que, mais uma vez, nas palavras de Horta, Grunberg e Monteiro (1999, p. 8),

O processo educativo, em qualquer área de ensino/aprendizagem, tem como objetivo levar os alunos a utilizarem suas capacidades intelectuais para a aquisição de conceitos e habilidades, assim como para o uso desses conceitos e habilidades na prática, em sua vida diária e no próprio processo educacional.

No processo educativo de História no município do Rio Grande, a primeira ideia é a visitação aos bens culturais rio-grandinos, isto é, ir até aos próprios locais onde são encontrados. A partir disso, iniciar-se-ia a construção da relação entre os conteúdos da disciplina e os bens culturais visitados. Esse ponto-chave deve-se ao fato de que a Educação Patrimonial fundamenta o desenvolvimento da ação educativa em etapas metodológicas, sendo a primeira delas a "observação", seguida pelo "registro", pela "exploração" e pela "apropriação". Com isso, o marco metodológico pauta-se na aplicação dessas etapas em cada um dos blocos de "conteúdos - bem culturais" idealizados. Para que isso se concretize, as etapas metodológicas adotadas aqui estão organizadas no "Guia Básico de Educação Patrimonial", do Instituto do Patrimônio Histórico e Artístico Nacional:

Quadro 1 - Etapas metodológicas para o desenvolvimento de práticas a partir da Educação Patrimonial

\begin{tabular}{|c|c|c|}
\hline Etapas & Recursos/Atividades & Objetivos \\
\hline 1) Observação & $\begin{array}{l}\text { Exercícios de percepção } \\
\text { visual/sensorial, por meio } \\
\text { de perguntas, } \\
\text { manipulação, } \\
\text { experimentação, } \\
\text { mediação, anotações, } \\
\text { comparação, dedução, }\end{array}$ & $\begin{array}{l}\text { Identificação do objeto / } \\
\text { função / significado; } \\
\text { Desenvolvimento da } \\
\text { percepção visual e simbólica. }\end{array}$ \\
\hline
\end{tabular}




\begin{tabular}{|c|c|c|}
\hline & jogos de detetive... & \\
\hline 2) Registro & $\begin{array}{l}\text { Desenhos, descrição } \\
\text { verbal ou escrita, } \\
\text { gráficos, fotografias, } \\
\text { maquetes, mapas e } \\
\text { plantas baixas. }\end{array}$ & $\begin{array}{l}\text { Fixação do conhecimento } \\
\text { percebido, aprofundamento } \\
\text { da observação e análise } \\
\text { crítica; } \\
\text { Desenvolvimento da } \\
\text { memória, pensamento lógico, } \\
\text { intuitivo e operacional. }\end{array}$ \\
\hline 3) Exploração & $\begin{array}{l}\text { Análise do problema, } \\
\text { levantamento de } \\
\text { hipóteses, discussão, } \\
\text { questionamento, } \\
\text { avaliação, pesquisa em } \\
\text { outras fontes como } \\
\text { bibliotecas, arquivos, } \\
\text { cartórios, instituições, } \\
\text { jornais, entrevistas. }\end{array}$ & $\begin{array}{l}\text { Desenvolvimento das } \\
\text { capacidades de análise e } \\
\text { julgamento crítico, } \\
\text { interpretação das evidências } \\
\text { e significados. }\end{array}$ \\
\hline 4) Apropriação & $\begin{array}{l}\text { Recriação, releitura, } \\
\text { dramatização, } \\
\text { interpretação em } \\
\text { diferentes meios de } \\
\text { expressão como pintura, } \\
\text { escultura, drama, dança, } \\
\text { música, poesia, texto, } \\
\text { filme e vídeo. }\end{array}$ & $\begin{array}{l}\text { Envolvimento afetivo, } \\
\text { internalização, } \\
\text { desenvolvimento da } \\
\text { capacidade de auto- } \\
\text { expressão, apropriação, } \\
\text { participação criativa, } \\
\text { valorização do bem cultural. }\end{array}$ \\
\hline
\end{tabular}

Fonte: HORTA; GRUNBERG; MONTEIRO, 1999, p. 11

O fundamento, por conseguinte, é a elaboração do processo de aplicação das etapas metodológicas, nas aulas de História, apresentadas em cada um dos conteúdos selecionados: "Introdução ao estudo da História", "Reforma e Contrarreforma", "Escravidão e abolição no Brasil império" e "Ditadura e democracia no Brasil". Desse modo, tem-se a metodologia da Educação Patrimonial como uma orientação a ser seguida para o estabelecimento das relações entre os conteúdos e os bens culturais rio-grandinos. O marco teórico e 
metodológico, portanto, está profundamente conectado aos preceitos e às etapas da Educação Patrimonial ao longo de toda sua execução.

Aqui, referindo-se ao início da aplicação das primeiras etapas metodológicas, é importante ressaltar que cada "[...] visita será positiva, se, ao finalizá-la, o aluno tiver uma compreensão coerente do lugar, de sua estrutura, de sua política, econômica, social e tecnológica, de seu funcionamento na época, da população que ali viveu, sonhou, trabalhou [...]" (GRUNBERG, 2000, p. 176). Destarte, a atividade não se encerra nas visitas. Elas são um dos pontos de partida para o desenvolvimento das demais etapas metodológicas da Educação Patrimonial e para que se chegue ao objetivo central de aproximação dos alunos aos conteúdos e aos bens culturais. Vale destacar que, embora fundamentado nessa metodologia bem definida, não se tem pretensões de impor uma visão "etapista" do processo educativo tal qual uma receita a ser seguida. A criação de roteiros liga-se ao necessário planejamento das aulas de História com a noção de que os planos não são diretrizes rígidas e inflexíveis, mas sim a base essencial para o desenrolar dos processos de ensino e de aprendizagem.

\section{O conteúdo curricular de História e o patrimônio rio-grandino: aproximações possíveis}

A ideia apresentada por este texto desdobra-se em pensar em outras situações de utilização do patrimônio rio-grandino nas aulas de História com a finalidade de aproximação dos estudantes ao que é apresentado teoricamente nas salas de aula. Outrossim, a preocupação em oferecer subsídios aos professores para esse trabalho também se faz presente, pois sabe-se que muitas vezes a carga horária e diversos outros entraves, como a carência de materiais didáticos, limitam a diversificação da atuação dos profissionais da educação e podem passar a ser impeditivos de outras práticas no ensino de História. Logo, alguns eixos alicerçadores deste texto passam a tomar forma cientes da necessidade de preparação de meios para a aplicação da Educação Patrimonial em conteúdos de História e na possibilidade de apoio aos professores a fim de orientar esse processo. 
Dessa forma, o olhar volta-se ao currículo tradicional de História na educação básica (anos finais do ensino fundamental e ensino médio), em Rio Grande, para uma seleção discricionária de conteúdos a serem aqui comtemplados de forma breve. Para tanto, optou-se pela escolha de um conteúdo de cada faixa temporal consolidada pela habitual divisão da História escolar. O processo decisório dos conteúdos leva em conta algumas das possibilidades oferecidas pelo patrimônio rio-grandino, para que ele seja de fato inserido no ensino de História por meio da Educação Patrimonial que "[...] também pode se desenvolver a partir do próprio estudo da história local ou da história pessoal dos alunos a fim de garantir o uso ampliado da noção de patrimônio cultural [...]" (SALVADORI, 2008, p. 38). Para tanto, os conteúdos escolhidos oferecem a possibilidade de contemplar, com a Educação Patrimonial, também o estudo da história local.

Por esse ângulo, nota-se que a intenção não é afastar o professor do currículo da disciplina, mas sim utilizar o próprio currículo como ferramenta para a criação de outras oportunidades de situações de aprendizagem aos alunos. Afinal,

[...] fazer uso de escalas de observação significa levar em consideração formas de descontinuidade presentes no mundo social efetivo. Toda realidade histórica maior [...] assume com certeza sua forma e seu sentido numa pluralidade de mundos sociais (REVEL, 2010, p. 443).

Para isso, entende-se o diálogo entre o patrimônio rio-grandino e seus significados com o conteúdo curricular de História como um meio de levar as escalas de observação da pesquisa em História para o ensino de História na educação básica. A "realidade histórica maior" presente na aula tradicional encontrar-se-ia, então, com a "pluralidade de mundos sociais" vivenciados pelos estudantes e professores no cotidiano rio-grandino permeado pela constante presença e (não)vivência do patrimônio.

Já é de conhecimento que foram selecionados os seguintes conteúdos: "Introdução ao estudo da História"; "Reforma e Contrarreforma"; "Escravidão e abolição no Brasil império"; "Ditadura e democracia no Brasil". Sendo assim, a ideia central passa a ser, por conseguinte, a proposição de situações de 
aprendizagem com a utilização do patrimônio rio-grandino para esses conteúdos, destacando-se que

A metodologia da Educação Patrimonial pode levar os professores
a utilizarem os objetos culturais na sala de aula ou nos próprios
locais onde são encontrados, como peças 'chave' no
desenvolvimento dos currículos e não simplesmente como mera
'ilustração' das aulas (HORTA; GRUNBERG; MONTEIRO, 1999, p. 9,
grifo nosso).

Portanto, a metodologia da Educação Patrimonial fundamenta a aproximação dos alunos aos conteúdos trabalhados por meio da utilização do próprio município. Ainda, faz-se valer na prática o entendimento de que "escalas diferentes implicam informações diferentes, possibilidades diversas de interpretação e de ação. Essa leitura estratificada da realidade social contribui para restituir a pluralidade das vozes que a compõem" (CERUTTI, 1998, p. 196). Isto posto, a finalidade neste ponto é a criação e a preparação de situações de aprendizagem práticas e concretas que relacionem o ensino de História aos bens culturais rio-grandinos. Para cada um dos conteúdos selecionados, a intenção é propor um caminho viável para essa aplicação metodológica no município.

Nesse momento, pensa-se em estabelecer a relação entre os conteúdos e os bens culturais rio-grandinos da seguinte maneira: "Introdução ao estudo da História" - Bibliotheca Rio-Grandense; "Reforma e Contrarreforma" - Igreja Nosso Senhor do Bom Fim (católica), Templo São Miguel (luterano) e Paróquia do Salvador (anglicana); "Escravidão e abolição no Brasil império" - cais do Porto Velho, Praça Tamandaré, Largo Dr. Pio e Praça Xavier Ferreira; "Ditadura e democracia no Brasil" - Câmara Municipal do Rio Grande (Legislativo), Prefeitura Municipal do Rio Grande (Executivo) e Fórum do Rio Grande (Judiciário). Para cada uma dessas relações, o intuito é preparar uma espécie de roteiro que garanta o suporte para a execução do planejamento individual de cada professor para esses conteúdos.

Sabe-se que "muitas vezes a educação patrimonial nas escolas se pauta apenas nas visitas dos tais 'espaços de memória', como se a História se limitasse a pontos determinados" (AQUINO, 2014, p. 27-28); todavia, o propósito aqui é o oposto dessa visitação limitada, pois articular-se-ia o bem cultural com 0 conteúdo previsto de História, com base na adequada utilização da metodologia da Educação Patrimonial. Destarte, a aproximação pretendida entre os sujeitos e 
os objetos das aulas poderia auxiliar também na melhor compreensão sobre os bens culturais do município e seus significados históricos e sociais.

Agora, passa-se a apresentar um estabelecimento prévio das relações a partir de algumas reflexões incipientes. O conteúdo de "Introdução ao estudo da História", previsto para o $6^{\circ}$ ano do ensino fundamental e $1^{\circ}$ ano do ensino médio, seria conectado via metodologia da Educação Patrimonial à Bibliotheca Rio-Grandense. Dessa maneira, o entendimento sobre os fundamentos da disciplina e do ofício do historiador poderiam vir a ser vivenciados pelos alunos por meio do contanto com o bem cultural rio-grandino que, por sua vez, passaria a ser ressignificado pela turma e/ou ganhar novos significados. Mais uma vez, a simples visita ao espaço como ilustração da aula não é suficiente para alcançar o proposto. Não há, portanto, o mero "passeio" ao local. As etapas metodológicas da Educação Patrimonial funcionam como a base para a estruturação desse e dos demais roteiros. O diálogo com os profissionais e a exploração da história da Bibliotheca, por exemplo, são caminhos possíveis para auxiliar no desenvolvimento do que está sendo proposto aqui.

No 70 ano do ensino fundamental e fim do $1^{\circ}$ ano do ensino médio está previsto o conteúdo de "Reforma e Contrarreforma", movimentos religiosos a partir do século XVI, iniciados na Europa, que dão origem às primeiras religiões protestantes e ao fortalecimento da doutrina da Igreja Católica. Com a Educação Patrimonial é possível conectar os alunos a esses conceitos utilizando os próprios bens culturais do município do Rio Grande. Logo, o que se pensa para esse tópico é um roteiro com três pontos de parada pelo Centro: Igreja Nosso Senhor Bom Fim, Templo São Miguel e Paróquia do Salvador. Nota-se que são três instituições religiosas de denominações diferentes, isto é, católica, luterana e anglicana, respectivamente. Consequentemente, pode ser possível traçar esse roteiro passando por esses três locais a fim de que o movimento religioso reformista dos protestantes e a resposta católica com a contrarreforma possam vir a ser aproximados da realidade dos sujeitos da aula de História.

A "Escravidão e abolição no Brasil império" está alocada no $8^{\circ}$ ano do ensino fundamental e $2^{\circ}$ ano do ensino médio, correspondendo a um amplo período histórico do país. Diante disso, destacou-se, de imediato, as temáticas da escravidão e da abolição. Aqui, para firmar a relação entre conteúdos e bens 
culturais, passa-se a pensar em um roteiro mais alongado pelo Centro Histórico do Rio Grande. Ele iniciaria no cais do Porto Velho, onde seria possível discorrer sobre o transporte dos africanos escravizados nos "tumbeiros" (embarcações com péssimas condições trazidas da África em direção à América Portuguesa) e sua chegada, passando para a Praça Tamandaré (antiga Geribanda) onde os escravizados coletavam água em poços instalados em meio a combros de areia e para o Largo Dr. Pio (antigo Largo das Quitandeiras) onde as escravizadas comercializavam seus quitutes, chegando finalmente à Praça Xavier Ferreira mais especificamente à "coluna comemorativa da libertação dos escravos", onde refletir-se-ia sobre o movimento abolicionista, a abolição, seus desdobramentos e seus símbolos como a própria "coluna".

Ainda, no 90 ano do ensino fundamental e $3^{\circ}$ ano do ensino médio, 0 conteúdo sobre "Ditadura e democracia no Brasil" teria sua relação trabalhada a partir da perspectiva da redemocratização do país e do ordenamento do Estado Democrático de Direito. Nesse caso, a proposição do roteiro por bens culturais rio-grandinos está ligada à visão iluminista dos três poderes da República (Legislativo, Executivo e Judiciário). Com base na Educação Patrimonial, os alunos seriam conduzidos a três espaços representativos (Câmara Municipal do Rio Grande, Prefeitura Municipal do Rio Grande e Fórum do Rio Grande) onde seria possível apresentar concretamente as bases democráticas retomadas pelo país após um longo período ditatorial entre 1964 e 1985 e, além disso, identificar os fundamentos essenciais de cada um dos três poderes. Então, relacionar-se-ia o conteúdo ao município e, por conseguinte, à realidade dos sujeitos das aulas e à essência democrática do funcionamento das instituições na atualidade.

\section{Considerações Finais}

Todos esses cenários desenhados levam em consideração que "numa realidade em que a carga horária reservada à disciplina História já se apresenta reduzida, faz-se necessário elaborar formas dinâmicas e eficazes de relacionar a educação patrimonial aos conteúdos canônicos" (VIANA; MELLO, 2013, p. 50). Sendo assim, o patrimônio e outros temas transversais não seriam responsáveis 
pela criação de mais disciplinas curriculares e a consequente maior fragmentação da construção do conhecimento. Contudo, pode-se mencionar que cada uma das dinâmicas inicialmente pensadas está respaldada pelas etapas metodológicas bem definidas da Educação Patrimonial. Aliás, a amplitude dessas considerações iniciais tende a ir sendo limitada por cada professor de acordo com suas vivências práticas.

Por fim, importante ressaltar que esse texto converge com a ideia de que a Educação Patrimonial "trata-se de um processo permanente e sistemático de trabalho educacional centrado no Patrimônio Cultural como fonte primária de conhecimento e enriquecimento individual e coletivo" (HORTA; GRUNBERG; MONTEIRO, 1999, p. 6) e que "não se trata, é claro, da criação de mais uma disciplina a ser incluída na grade curricular" (SALVADORI, 2008, p. 36). Em outras palavras, o foco está voltado para o ensino de História e os profissionais da área, entrando em consonância com o trabalho do patrimônio como tema transversal nas escolas e nas aulas de História, apresentando-se como uma possibilidade factível de prática e de pesquisa - em um diálogo entre diferentes escalas de análise - ao longo de sua execução e como futura base de apoio.

\section{Referências}

AQUINO, Cristiane Valdevino de. Educação Patrimonial na sala de aula: a escola como patrimônio cultural. In: TOLENTINO, Átila Bezerra (org.). Educação patrimonial: diálogos entre escola, museu e cidade. João Pessoa: Instituto do Patrimônio Histórico e Artístico Nacional, 2014. p. 25-31.

BENSA, Alban. Da micro-história a uma antropologia crítica. In: REVEL, Jacques (org.). Jogos de escalas: a experiência da microanálise. Rio de Janeiro: Editora Fundação Getúlio Vargas, 1998. p. 39-76.

CERUTTI, Simona. Processo e experiência: indivíduos, grupos e identidades em Turim no século XVII. In: REVEL, Jacques (org.). Jogos de escalas: a experiência da microanálise. Rio de Janeiro: Editora Fundação Getúlio Vargas, 1998. p. 173202.

FARINATTI, Luís Augusto. Construção de séries e micro-análise: notas sobre o tratamento de fontes para a história social. Anos 90, Porto Alegre, v. 15, n. 28, p. 57-72, jul. 2008. 
FLORÊNCIO, Sônia Regina Rampim. Educação Patrimonial: um processo de mediação. In: TOLENTINO, Átila Bezerra (org.). Educação patrimonial: reflexões e práticas. João Pessoa: Superintendência do Iphan na Paraíba, 2012. p. 22-29.

GIL, Carmem Zeli de Vargas; ALMEIDA, Doris Bittencourt. Patrimônios da educação: o ensino e a pesquisa. Revista Latino-Americana de História, São Leopoldo, v. 2, p. 121-134, ago. 2013.

GRUNBERG, Evelina. Educação Patrimonial: Utilização dos bens culturais como recursos educacionais. Cadernos do CEOM, Chapecó, n. 12, p. 159-180, 2000.

HORTA, Maria de Lourdes Parreiras; GRUNBERG, Evelina; MONTEIRO, Adriane Queiroz. Guia básico de educação patrimonial. Brasília: Instituto do Patrimônio Histórico e Artístico Nacional: Museu Imperial, 1999.

IPHAN - INSTITUTO DO PATRIMÔNIO HISTÓRICO E ARTÍSTICO NACIONAL. Educação Patrimonial. Brasília: IPHAN, 2014. Disponível em:

http://portal.iphan.gov.br/pagina/detalhes/343. Acesso em: 9 fev. 2019.

LONDRES, Cecília. O Patrimônio Cultural na formação das novas gerações: algumas considerações. In: TOLENTINO, Átila Bezerra (org.). Educação patrimonial: reflexões e práticas. João Pessoa: Superintendência do Iphan na Paraíba, 2012. p. 14-21.

MAGALHÃES, Leandro Henrique; ZANON, Elisa; BRANCO, Patrícia Martins Castelo. Educação patrimonial: da teoria à prática. Londrina: Ed. UniFil, 2009.

OLIVEIRA, Margarida Maria Dias de. O ensino de história, a memória e o patrimônio cultural. História \& Ensino, Londrina, v. 15, p. 119-130, ago. 2009.

REVEL, Jacques. Micro-história, macro-história: o que as variações de escala ajudam a pensar em um mundo globalizado. Revista Brasileira de Educação, Rio de Janeiro, v. 15, n. 45, p. 434-444, set./dez. 2010.

ROSSI, Alessandra Vanessa. Patrimônio cultural: entenda e preserve: guia de atividades de educação patrimonial. Campinas: Prefeitura Municipal de Campinas: Secretaria Municipal de Cultura, 2009.

SALVADORI, Maria Ângela Borges. História, ensino e patrimônio. Araraquara: Junqueira\&Marin, 2008.

VIANA, Iamara da Silva; MELLO, Juçara da Silva Barbosa de. Educação patrimonial e ensino de história: diálogo. Encontros, Rio de Janeiro, n. 20, p. 4962, 2013. 